C. Málaga-Chuquitaype, S. Kaminski, A. Y. Elghazouli, A. Lawrence (2014), Proceedings of the Institution of Civil Engineers, Structures and Buildings 167 December 2014 Issue SB12 Pages 693-703 http://dx.doi.org/10.1680/stbu.13.00090

\title{
Seismic response of timber frames with cane and mortar walls
}

C. Málaga-Chuquitaype, S. Kaminski, A. Y. Elghazouli, A. Lawrence

\section{Abstract}

This paper describes an experimental study into the seismic behaviour of low-cost walls incorporating timber frames with composite cane and cement mortar panels. Five cyclic tests on full scale wall specimens of different geometric and material characteristics are described. The test set-up, wall configurations and material properties are first introduced followed by a detailed account of the experimental results and observations. Based on the results from the tests, the main behavioural features are discussed and the salient response parameters such as stiffness, strength, energy dissipation and ductility are examined. Particular emphasis is given to the assessment of key construction provisions such as mortar strength, galvanized wire mesh reinforcement and the presence of windows. The cyclic tests reported offer direct information on the lateral force-displacement response of the walls and their energy dissipation characteristics. Finally, simple expressions for determining the overall stiffness and capacity of the timber frame composite cane and mortar walls are proposed. Besides providing essential information for the future validation of more detailed numerical procedures, the experimental results presented in this paper also demonstrate the suitability of this form of low-cost construction for resisting deformation demands typical of large magnitude earthquakes.

\section{Keywords chosen from ICE Publishing list}

Seismic engineering; composite structures; timber structures.

\section{List of notation}

$a \quad$ is the length of an individual panel

$b \quad$ is the height of an individual panel

$E \quad$ is the modulus of elasticity of the cement mortar

$F \quad$ is the lateral in-plane load applied to the panel

$l_{s} \quad$ is the length of the equivalent diagonal strut

$t_{e f f} \quad$ is the effective thickness of the panel

$\sigma_{c} \quad$ is the compressive strength of the cement mortar

$\sigma_{t} \quad$ is the tensile strength of the cement mortar

$\theta \quad$ is the angle between the diagonal compression strut and the horizontal 


\section{Introduction}

The collapse of non-engineered construction constitutes a dominant cause of fatalities during earthquakes, especially in the developing world (Bilham, 2009). Recent events like the Haiti Earthquake of 2010, which resulted in casualties of around $15 \%$ of the 2.5 million population of Port-au-Prince (Bilham, 2010), highlight the urgent need for the provision of low-cost earthquake-resistant housing for developing nations. To this end, adequate design guidance as well as construction techniques and maintenance plans need to be developed, that ideally make use of local available materials and practices.

Wattle-and-daub construction constitutes a traditional housing style with a history of good seismic performance that continues to be used in many countries around the world (López et al., 2004). These buildings use locally sourced materials such as timber, cane and bamboo to form a composite wall matrix, which is then plastered in mud to form shear walls in houses. Such houses are inexpensive, sustainable and relatively seismically-resistant when wellconstructed and maintained (López et al., 2004). However, they require a significant amount of maintenance and are not popular in some communities due to their association with low-income social groups (Kaminski, 2013). A bespoke structural system has been developed by Arup and the EI Salvadorean Non-Governmental Organisation (NGO) REDES for its use in the earthquake-prone country of El Salvador, and tested at Imperial College London (Elghazouli et $a l, 2013)$. The design uses a structural timber frame with engineered connections, clad with local cane, both treated against insect attack, and plastered with cement mortar reinforced with galvanized (chicken) wire mesh. The foundation consists of a reinforced concrete slab with ground beams. The walls are elevated on two courses of reinforced hollow. The roof consists of lightweight cement fibreboard sheeting on a timber frame. The design builds upon a vernacular form of wattle-and-daub construction as well as research into similar forms of low-cost housing in Latin America (Kaminski, 2013).

This paper presents and discusses the results of a series of cyclic tests performed in order to characterise the seismic behaviour of the newly developed wall panels. A total of five full-scale wall specimens with different geometrical configurations, mortar strengths and wire mesh locations were examined. Subsequent sections of this paper describe the arrangements used for the full-scale tests and provide a detailed description of the specimens. The main experimental results are then presented followed by a discussion on the key behavioural observations such as lateral stiffness, capacity and failure mechanisms of this type of structure, and their implications on seismic performance and design.

\section{Experimental set-up and details}

\subsection{Testing arrangement}


Figure 1(a) presents the plan and elevation of the test arrangement employed, whereas Figure 1 (b) gives a general view of a typical specimen during testing. Due to its relative lateral flexibility, only the portion of the wall composed of timber frames with cane and mortar panels to be constructed above the layers of reinforced hollow blockwork was examined herein giving a net specimen height of $1850 \mathrm{~mm}$. A hydraulic actuator operating in displacement control was employed to apply lateral deformations to the specimen through a loading beam situated at a height of $1700 \mathrm{~mm}$ from the strong floor, this height corresponds to the bottom of the window lintel and represents a loading line that favours the full lateral deformation of the penal along its height without imposing excessive localized stress concentrations in any vertical timber stud or unrealistic uplift actions. A loading beam formed of two parallel U100 Channel sections was employed as depicted in Figure 1. The channel sections were connected to the specimens via $10 \mathrm{~mm}$ bolts designed to yield during testing in order to encourage a uniform load distribution along the length of the panel. These steel bolts were connected to the loading beam through vertically slotted holes so as to accommodate possible differential vertical movement between individual sections of the specimen. Lateral restraint was provided by a $100 \times 100 \times 10$ Square Hollow Section column guiding the loading beam at its extreme. Additional lateral stability was supplied to the wall by the 1 metre-long perpendicular panels constructed at each end of all specimens. Four nominal loads of approximately $2 \mathrm{kN}$ acting vertically were applied in the perpendicular walls at the beginning of each test by means of strong stressed ties attached to the steel base as presented in Figure 1. The total vertical load applied was continuously monitored throughout the test by means of load cells attached to the top of the Specimen (Figure 1(b)). All specimens were fixed at the base to a steel rig through sixteen $10 \mathrm{~mm}$ steel bolts. The steel rig base was constructed from welded square hollow sections (SHS 100x10) pre-stressed to the strong floor as depicted in Figure 1(a).

Lateral displacements and the corresponding forces were recorded by the load cell and displacement transducer incorporated within the actuator. Displacement transducers and stringpotentiometers installed at selected locations along the wall were used to monitor in-plane deformations and distortions. The relative displacements between the loading beam and various points of the wall were measured in order to allow for the correction of the relative motion caused by the plastic deformation of the bolts within the loading beam. All tests were conducted under displacement-control. The cyclic testing protocol, based on the EN12512 protocol (CEN, 2005), shown in Figure 2 was used. In this figure, $\Delta$ represents the applied displacement and $\Delta_{y}$ is the estimated yield displacement.

\subsection{Specimens and materials}

A total of five full-scale walls were tested. A summary of the test series is given in Table 1, which includes the geometric details, average values of mortar strength and the distribution of layers of cane and wire mesh within the panel rendering. Figure 3 illustrates the two geometrical configurations utilised (i.e. Type A and Type B in Table 1). Specimens P1 to P4 consist of a $3 \mathrm{~m}$ 
by $2 \mathrm{~m}$ wall with a $1 \mathrm{~m}$ by $1 \mathrm{~m}$ window placed at the middle of the internal panel as illustrated in Figure 3(a) (Type A) whereas Specimen P5 comprises two separate $1 \mathrm{~m} \times 2 \mathrm{~m}$ walls acting in series without the contribution of the wall segments above and below the window (which act as coupling beams) (Type B). The configurations of specimens were selected in order to study the influence of different geometrical configurations as well as different locations of the wire mesh within the cement rendering.

Grade 16 softwood studs of 2"x4" were employed for the timber frames in all specimens. All specimens incorporated a layer of horizontally placed caña brava canes (gynerium sagittatum) of $10-30 \mathrm{~mm}$ diameter nailed to the exterior of the timber frames. The $3 \mathrm{~m}$ long canes were pretreated by immersion in boron and shipped directly from Costa Rica. A lightweight galvanized wire mesh with hexagonal $25 \mathrm{~mm}$ holes was nailed to the timber frame (i) before placing the cane (i.e. fitted towards the interior) in Specimens P2, P3 and P5; or (ii) after nailing the cane (i.e. fitted towards the exterior) in Specimen P1. In the case of Specimen P4, the wire mesh was eliminated. Finally, approximately $20 \mathrm{~mm}$ thick mortar layers were placed at each side of the wire mesh forming a $60 \mathrm{~mm}$ thick mortar panel. A simple sharp sand and Portland Cement mixture was used for the mortar, and the corresponding mean values of compressive strength as obtained from standard cube $(100 \times 100 \times 100 \mathrm{~mm})$ samples at the day of testing are reported in Table 1. Additionally, 600x100 Simpson Strong-Tie Light Engineered Straps (SSTLES) were used for the stud-to-sole plate tie-downs at the extremes as illustrated in Figure 4, with a nominal tensile working load of $4 \mathrm{kN}$ (Simpson Strong-Tie, 2013).

\section{Results and observations}

The main response parameters obtained from the tests are summarised in Table 2, and the key results are presented in Figures 5 to 8 . The initial stiffness reported represents the tangent stiffness. The maximum measured force $\left(F_{\max }\right)$ and corresponding displacement $\left(\Delta_{\mathrm{u}}\right)$ are also presented in Table 2. All values reported in this section correspond to the force and displacement at the location of the load application (i.e. at a height of $1700 \mathrm{~mm}$ from the strong floor, see Figure 1). Table 2 also includes the hysteretic energy dissipated per unit displacement. The hysteretic energy is defined herein as the summation of the areas enclosed by the force displacement curves. The experimental results and observations from the five cyclic tests, summarised in Tables 1 and 2, are presented and discussed in subsequent sections with particular focus on the hysteretic response, force-displacement envelopes and energy dissipation.

\subsection{Hysteretic response}

Figure 5 presents the hysteretic lateral force-displacement curves obtained for the five composite timber frame and cane-mortar walls examined. It is clear from this figure that all specimens exhibited a stable hysteretic behaviour under low to moderate cyclic demands with a clear transition between elastic and inelastic response. First signs of cracking appeared at a 
drift of around $0.1 \%$ while significant damage to the mortar, especially to the layers without mesh, was evident for drifts larger than $0.3-0.6 \%$. As the displacement demands increased, residual deformations were developed in all specimens due to increasing cracking, crushing and spalling of the mortar, as well as the accumulation of plastic deformation within the timber frame connections, This in turn led to flattening of the shape of the hysteresis loops during the reversal of loading (i.e. pinching), caused by the reduction in the overall resistance of the walls. Nevertheless, an increase in stiffness occurred when the previously attained level of displacement was achieved. As expected, this pinching behaviour was observed in all specimens. Pinching became more noticeable when no wire mesh was provided as in the case of Specimen P4 mainly due to the rapid loss of integrity of the cement mortar. In addition, the hysteretic response of all tested walls features a post-capping negative tangent stiffness that onsets at different displacement levels depending on the specimen under consideration as discussed below.

Specimens P1, P2, P3 and P4, in Figures 5 (a), (b), (c) and (d), respectively, experienced different reloading branches for each cycle accompanied by noticeable strength degradation in the order of $-25 \%$ at peak displacements. These noticeable levels of strength degradation occurred even before reaching the deformation level associated with the strength cap which for Specimens P1 and P2 corresponds to $40 \mathrm{~mm}$ of lateral displacement. On the other hand, no post-capping negative stiffness region was observed for Specimen P3. In the case of Specimen P4 (Figure 5(d)) with no wire mesh, the deformation associated with strength capping was reached earlier (i.e. at a lateral displacement of $25 \mathrm{~mm}$ ) after which severe strength deterioration was observed with the last cycle at $55 \mathrm{~mm}$ reaching strengths of only $28 \%$ the panel's overall maximum capacity. Moreover, both the unloading and reloading stiffness observed in Specimen P4 (Figure 5(d)) exhibited a more accelerated rate of deterioration in comparison with Specimens P1 to P3 (Figures 5 (a), (b) and (c)). This demonstrates the benefit of the wire mesh in enhancing the overall ductility of the panel by holding the cement render together after severe cracking. On the other hand, smaller levels of strength deterioration were observed in Specimen P5 (Figure 5(e)) in direct relationship with the lower lateral capacity reached by the two panels in series (Type B) relative to the other specimens with coupling beams (Specimens P1 to P4 of Type A)). The strength cap displacement in Specimen 5 was attained at around $35 \mathrm{~mm}$ of lateral deformation.

\subsection{Influence of material and geometric parameters}

The observations discussed above can be further assessed with reference to Figure 6 which presents the envelope of the hysteresis curves for all specimens tested. This section discusses the influence of specific material and geometric parameters on the force-displacement envelopes depicted in Figure 6 with particular emphasis on the wire mesh location, cement mortar strength and panel geometry. 


\subsubsection{Location of wire mesh}

The effects of the location of the wire mesh within the thickness of the panel can be evaluated with reference to the response of Specimens P1 and P2 where the mesh was placed towards the exterior face in the former and towards the interior face in the latter while all other parameters remained unaltered. It can be seen from the results presented in Figure 6 and Table 2 that the initial stiffness of the wall is relatively insensitive to the location of the mesh. However, after the initiation of cracking in the cement mortar, at a lateral resistance of around $20 \mathrm{kN}$ in both specimens, the wall with the mesh fixed towards the exterior face (Specimen P1) exhibits a slightly stiffer response that leads to a maximum lateral capacity of $46 \mathrm{kN}$ in comparison with the $42 \mathrm{kN}$ achieved in Specimen 2 (where the mesh is placed towards the interior). These effects are related to the relative stiffness contribution of the outer and inner layers of mortar within the wall (see Detail A in Figure 3(a)). The discontinuity of the interior layer of mortar imposed by the vertical timber studs breaks up the single panel into a number of smaller panels, the sum of which is less stiff and weaker than a single continuous panel. Consequently, by maintaining the integrity of the exterior mortar and delaying the spalling of rendering in the outer face, Specimen $\mathrm{P} 1$ is able to reach a nearly $10 \%$ increase in its maximum capacity in comparison with Specimen P2. However, it should be noted that preventing spalling of mortar towards the interior of the dwelling ought to be favoured since this may constitute a significant lifethreatening hazard for the inhabitants. The effectiveness of the wire mesh in preventing mortar spalling and reducing the above mentioned hazard is evident from Figure 7 which presents the final state of the interior face of Specimens $\mathrm{P} 1$ and $\mathrm{P} 2$ after testing.

In addition to the location of the wire mesh within the wall thickness, another configuration of interest is represented by the case in which the wire mesh is not employed. This case is studied in Specimen P4. Notwithstanding the difference in the mortar strength, $\sigma_{c}$, between Specimens P2 $\left(\sigma_{c}=5 \mathrm{MPa}\right)$ and $\mathrm{P} 4\left(\sigma_{c}=3 \mathrm{MPa}\right)$ caused by inherent differences in the mortar mixes, their force-displacement envelopes presented in Figure 6 are comparable. It is apparent from this figure that the lack of wire mesh in Specimen P4 causes a more abrupt and severe loss of strength after $25 \mathrm{~mm}$ of lateral displacement, and a complete failure of the specimen at $40 \mathrm{~mm}$. Conversely, the provision of the wire mesh in Specimen P2 induces a more gradual degradation in strength with significant levels of lateral resistance still observable after $40 \mathrm{~mm}$ of deformation. As explained before, this difference in behaviour is brought about by the wire mesh acting to prevent spalling of the mortar hence maintaining much of the original load path (see Section 4.2) . Besides, the wire mesh also facilitates the mortar placement process and therefore improves its quality and compaction.

\subsubsection{Cement mortar strength}

The mortar strength is shown to have a direct influence on the maximum lateral strength of the wall. This can be observed by comparing the results of Specimens P2 and P3 in which the only parameter varied is the mortar strength, as shown in Figure 6 and in Table 2. A 2.4 times 
increase in the strength of the mortar (from $5 \mathrm{MPa}$ in Specimen P2 to $12 \mathrm{MPa}$ in Specimen P3) results in a nearly $20 \%$ increment in the maximum lateral force (from $42.1 \mathrm{kN}$ in Specimen P2 to $50 \mathrm{kN}$ in Specimen P3). This is explained further in Section 4.2.

\subsubsection{Specimen geometry}

The influence of the panel geometry is examined here by varying the configuration of the window aperture as depicted in Figure 3. In this figure, Type A represents a 3 metre long wall with a 1 by 1 metre window whereas Type $B$ is formed by two separate 1 metre panels acting in series. Eliminating the contribution of coupling beams can cause a significant reduction in the initial stiffness and some reduction of the capacity of the panel. This can be observed by comparing the force-displacement envelopes for Specimen P2 (Type A) and Specimen P5 (Type B), as presented in Figure 6 and Table 2. Connecting the panels with the coupling beams increased the initial wall stiffness by about $75 \%$ with respect to the two separate panels. Similarly, the coupling beams and, to some extent, the stronger mortar of Specimen P2 accounted for a nearly $50 \%$ enhancement in its maximum force $\left(F_{\max }=42.1 \mathrm{kN}\right)$ when compared with Specimen P4 $\left(F_{\max }=27.7 \mathrm{kN}\right)$.

\subsection{Energy dissipation and ductility}

In general, the timber frame and composite cane mortar panels examined in this study exhibited good levels of ductility and energy dissipation. An assessment of the energy dissipation in all specimens is presented in Figure 8. The curves depict the cumulative dissipated energy versus cumulative displacement, whilst the rates of energy dissipated per unit rotation (between 40 and $60 \mathrm{~m}$ of cumulative displacement) are given in Table 2. As expected, there is a direct relationship between the capacity of the Specimen and its energy dissipation capabilities. Accordingly, Panels P1 and P3 exhibited comparatively high levels of energy dissipation with dissipation rates in the order of 1.6 and 2.5 times those observed for Specimens P4 and P5, respectively.

\section{Estimation of design parameters}

The experimental results presented in the previous section provide essential data for the future development and validation of detailed analytical and numerical models with a view to predicting the response of timber frames with composite cane and mortar panels under seismic loading conditions. However, in light of the above results, this section discusses and offers an evaluation of key wall response parameters such as deformation mechanisms, stiffness and capacity that can be of direct relevance to practical design application.

\subsection{Deformation modes}

Based on the experimental observations, it is considered that the panel acts fully compositely between the timber, cane and mortar during the initial stages of the response. The wall portions above and below the window, acting as coupling beams, improving the initial stiffness and 
strength of the panel by coupling the behaviour of the two adjacent panels. However, the coupling beams experience the greatest damage initially, after which the remaining side panels must resist the load largely independently. With vertical tie-down straps on one end only (none are used at the internal studs trimming the windows), each of these panels has resistance in one direction only. As the load increases, instability of the compression strut and associated cracking, buckling and spalling of mortar, as well as crushing in areas of stress concentration, occur. The use of a steel mesh reduces the extent of cracking of the panel and improves the stability of the compression strut primarily on the side of the panel on which it is used.

\subsection{Initial stiffness}

A conservative estimate of the initial stiffness of the walls can be obtained by considering the behaviour of the portion of the panel within the vertical timber studs resisting shear which can be idealized as an equivalent diagonal strut in compression. Therefore, the stiffness of each individual internal panel, $K_{i}$, can be evaluated as:

$$
K_{i}=\frac{E w t_{e f f}}{l_{s}}
$$

1.

Where $t_{\text {eff }}$ is the effective thickness of the wall, $l_{s}$ and $w$ are the length and width of the diagonal strut, respectively; and $E$ is the modulus of elasticity of the cement mortar which can be estimated as a function of its compressive strength $\left(\sigma_{c}\right.$, in $\left.\mathrm{kg} / \mathrm{cm}^{2}\right)$ as (Serrano-Guzman \& Perez-Ruiz, 2010):

$E=2500 \sigma_{c}^{0.5}$

2.

If $a$ is the length of each individual panel and $b$ its height, then the length of the compression strut, $l_{s}$, is defined by:

$l_{s}=\sqrt{a^{2}+b^{2}}$

3.

and the strut width, $w$, can be estimated from previous studies on brick and concrete infills (Holmes, 1961) as:

$w=l_{s} / 3$

4. 


\subsection{Plastic capacity}

A first approach, leading to reasonably conservative estimates of capacity, would be to ignore the contribution of the wire mesh for the estimation of maximum resisting forces. In this case, the capacity of the mortar panel could be obtained by evaluating the flexural capacity of the corresponding equivalent diagonal strut by assuming a certain eccentricity $e_{o}$, in the middle of the panel. To this end, the lateral force, corresponding to a tensile failure of the mortar in the interior side of the wall $\left(F_{i}\right)$ can be estimated as:

$$
F_{i}=\frac{\sigma_{t} t_{e f f}{ }^{2} w}{6 e_{o}} \cos \theta
$$

5.

where $\sigma_{t}$ is the tensile strength of the cement mortar which can be estimated on the basis of the mortar compressive resistance, $\sigma_{c}$, as described in previous studies on cement mortars (Appa Rao, 2001) as:

$$
\sigma_{t, c a p}=0.3\left(\sigma_{c}\right)^{0.55}
$$

6.

It is important to note that at this stage in the response, each of the panels contributes in in one direction only as explained above.

Figure 9 presents comparisons between the experimental force-displacement envelopes and the elastic-perfectly plastic estimations obtained by means of the expressions described previously in this section. An effective wall thickness of $40 \mathrm{~mm}$ was assumed for the estimation of initial stiffness by neglecting the relative compression stiffness of the cane-mortar composite (approximately $20 \mathrm{~mm}$ thick). Similarly, an effective wall thickness of 20-30 mm was employed for the calculations of plastic capacity reflecting the loss of a portion of the outer mortar layer due to cracking and spalling. Also, eccentricities in the middle of the panel in the order of $1 / 1000$ of its length were assumed. It is clear from Figure 9, that the suggested simplified expressions provide a good estimation of the stiffness within $\pm 10 \%$ in all cases. Likewise, the expressions for capacity described here offer a reasonable lower bound estimate of the lateral resistance in all specimens. The additional strength observed in Specimens P1 to P3 is supplied by the inner mortar layer remaining largely intact (due to the stabilising effect of the wire mesh). These effects would be further enhanced by the presence of the window lintel in Specimens P1 to P3.

\subsection{Detailing for ductility}


The experimental results have shown that the details here employed, except Specimen P4, are able to sustain drift demands in excess of $3.5 \%$ with less than $20 \%$ deterioration in peak strength. These levels of deformation capacity exceed the drift demands associated with most seismic design scenarios for this type of construction. Importantly, the provision of wire mesh was shown to be important in achieving a more ductile lateral response. In the case of Specimen P4, in which the wire mesh was eliminated, an earlier failure drift of $2.6 \%$ was observed, where the drift at failure is defined as the deformation level at which a $20 \%$ reduction in the peak strength is attained.

\section{Conclusions}

This paper examined the in-plane behaviour of walls formed of timber frames with cane and mortar panels for low-cost housing in developing countries affected by earthquakes. The results of five cyclic tests on full-scale specimens were described and discussed in detail. The experimental programme enabled a direct assessment of the influence of a number of key considerations, such as the mortar strength, wall geometry and wire mesh location on the overall lateral response of these walls. The test results also provide essential information for the future validation of detailed analytical models.

As expected, the cement mortar strength was found to be proportional to the plastic capacity of the wall. It was observed that the inelastic response exhibited by this type of walls can be improved by incorporating a layer of wire mesh reinforcement. This wire mesh maintains the integrity of the cement mortar and stabilises the compression strut after cracking, thus delaying the onset of significant strength deterioration and preventing dangerous spalling of mortar. It was also shown that coupling beams can have a significant contribution to the overall stiffness and capacity of the wall.

The tests highlight the relatively stable hysteretic response of walls formed by timber frames and cane and mortar render. Reasonably good levels of energy dissipation were observed in all specimens, although the pinching behaviour was more pronounced for walls with higher capacities. In particular, important strength degradation was observed when no wire mesh was provided in the case of Specimen P4. All walls tested achieved cumulative displacements in the order of $80 \mathrm{~mm}$ before experiencing extensive strength deterioration. Furthermore, drifts of more than $3.5 \%$ were achieved before a $20 \%$ deterioration in peak strengths was observed in all specimens except for Specimen P4 which did not incorporate a layer of wire mesh. These deformation capacities are beyond the demands expected under typical design scenarios. Finally, the applicability of simplified expressions to estimate response parameters of the walls studied were assessed. These simplified procedures provide reasonable preliminary estimates of the plastic capacity of the panels and their initial stiffness. Although the conclusions reached in this study would benefit from further investigations covering a wider range of wall configurations and more extensive verification tests, the consistency of experimental findings, 
coupled with the proposed simple expressions, indicate the suitability of this form of low-cost construction for earthquake-prone regions in developing countries.

\section{Acknowledgements}

The financial support of the Institution of Civil Engineers through its Research and Development Enabling Fund for the research described in this paper is gratefully acknowledged. The authors would also like to thank Engage for Development, the technical staff of the Structures Laboratories at Imperial College London, particularly Mr. R. Millward and Mr S. Algar, for their assistance with the experimental work, and also all of the volunteers who assisted in the construction of the panels.

\section{References}

Bilham R (2009) The seismic future of cities. Bulletin of Earthquake Engineering 7:839-887

Bilham R (2010) Lessons from the Haiti earthquake. Nature 878-879

CEN (2005) EN12512, Timber structures - Test methods - Cyclic testing of joints made with mechanical fasteners Comité Européen de Normalisation, Brussels.

Elghazouli AY, Málaga-Chuquitaype C, Lawrence A, Kaminski S and Coates K (2013) Seismic testing of sustainable cane and mortar walls for low-cost housing in developing countries. Institution of Civil Engineers, Research and Development Enabling Fund, Project Report

Gonzalez, G., Gutierrez, J. (2003) Cyclic Load Testing of Bamboo Bahareque Shear Walls for housing protection in Earthquake Prone Areas. Materials and Structural Models National Laboratory, School of Civil Engineering, University of Costa Rica

Holmes M (1961) Steel frames with brickwork and concrete infilling. Proceedings of the Institution of Civil Engineers 19:473-478

Kaminski, S. (2013) Engineered Bamboo Houses for Low-Income Communities in Latin America. The Structural Engineer 91:14-23

López M, Bommer J and Méndez P (2004) The Seismic Performance of Bahareque Dwellings in El Salvador. 13th World Conference on Earthquake Engineering. Vancouver, Canada

Appa Rao G. (2001) Generalization of Abrams' law for cement mortars. Cement and Concrete Research 31:495-502

Simspon Strong-Tie (2013) HRS/ST/PS/HST/HTP/LSTA/LSTI/MST/MSTA/MSTC/MSTI Strap Ties Installer's pocket guide, http://www.strongtie.com/ttp/catalogs/SINSTALL09.pdf\#page=36 (accessed: 08/07/2013)

Serrano-Guzman M, Perez-Ruiz, D (2010) Analisis de sensibilidad para estimar el modulo estatico del concreto, Concreto y Cemento. Investigación y Desarrollo, 2:17- 30.

\section{Table captions.}


Table 1. Summary of test program

Table 2. Summary of test results

Figure captions (images as individual files separate to your MS Word text file).

Figure 1. Experimental set-up - Elevation and plan view (units in metre) (a), General view (b) Figure 2. Loading protocol

Figure 3. Details of panel configurations - Type A (a), Type B (b)

Figure 4. Detail of the steel straps at the specimen ends

Figure 5. Force-displacement hysteresis - Specimen P1 (a), Specimen P2 (b), Specimen P3

(c), Specimen P4 (d), Specimen P5 (e)

Figure 6. Envelopes of the force-displacement hysteresis

Figure 7. Damage state of the interior face at the end of test - Specimen P1 (a), Specimen P2 (b)

Figure 8. Cumulative energy dissipation

Figure 9. Comparison of envelope of cyclic response and predicted force displacement relationships - Specimen P1 (a), Specimen P2 (b), Specimen P3 (c), Specimen P4 (d), Specimen P5 (e) 
Table 1. Summary of test program

\begin{tabular}{|l|c|c|c|c|c|}
\hline Specimen & P1 & P2 & P3 & P4 & P5 \\
\hline Panel geometry & Type A & Type A & Type A & Type A & Type B \\
\hline Exterior face rendering* & $\begin{array}{c}\text { Cane }+ \\
\text { wire mesh } \\
+ \text { mortar }\end{array}$ & $\begin{array}{c}\text { Cane }+ \\
\text { mortar }\end{array}$ & $\begin{array}{c}\text { Cane }+ \\
\text { mortar }\end{array}$ & $\begin{array}{c}\text { Cane }+ \\
\text { mortar }\end{array}$ & $\begin{array}{c}\text { Cane }+ \\
\text { mortar }\end{array}$ \\
\hline Interior face rendering* & Mortar & $\begin{array}{c}\text { Wire mesh } \\
+ \text { mortar }\end{array}$ & $\begin{array}{c}\text { Wire mesh } \\
+ \text { mortar }\end{array}$ & Mortar** & $\begin{array}{c}\text { Wire mesh } \\
+ \text { mortar }\end{array}$ \\
\hline Mortar strength [MPa] & 5 & 5 & 12 & 3 & 3 \\
\hline
\end{tabular}

${ }^{*}$ The order of layers corresponds to inner face to outer face progression

${ }^{* *}$ No wire mesh employed in this specimen

Table 2. Summary of test results

\begin{tabular}{|l|c|c|c|c|c|}
\hline Specimen & P1 & P2 & P3 & P4 & P5 \\
\hline Initial stiffness $[\mathrm{kN} / \mathrm{mm}]$ & 15 & 14 & 13 & 13 & 8 \\
\hline Maximum load, $\mathrm{F}_{\max }[\mathrm{kN}]$ & 46 & 42.1 & 50.3 & 37.2 & 27.7 \\
\hline Displacement at $\mathrm{F}_{\max }[\mathrm{mm}]$ & 25 & 25 & 55 & 25 & 35 \\
\hline Rate of energy dissipation $[\mathrm{kJ} / \mathrm{m}]$ & 0.122 & 0.083 & 0.111 & 0.075 & 0.0475 \\
\hline
\end{tabular}


a) Elevation and plan view (units in metres)
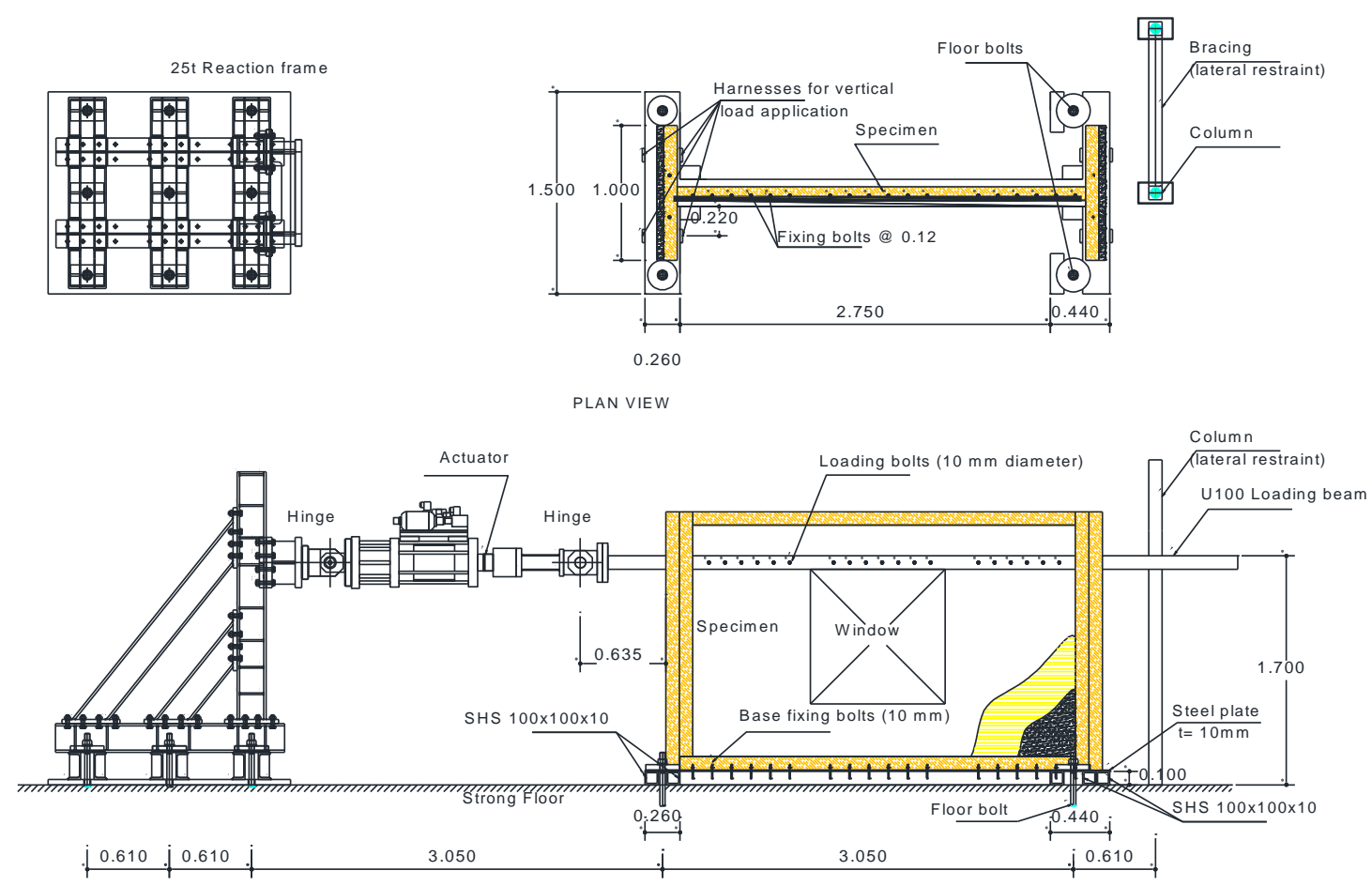

b) General view

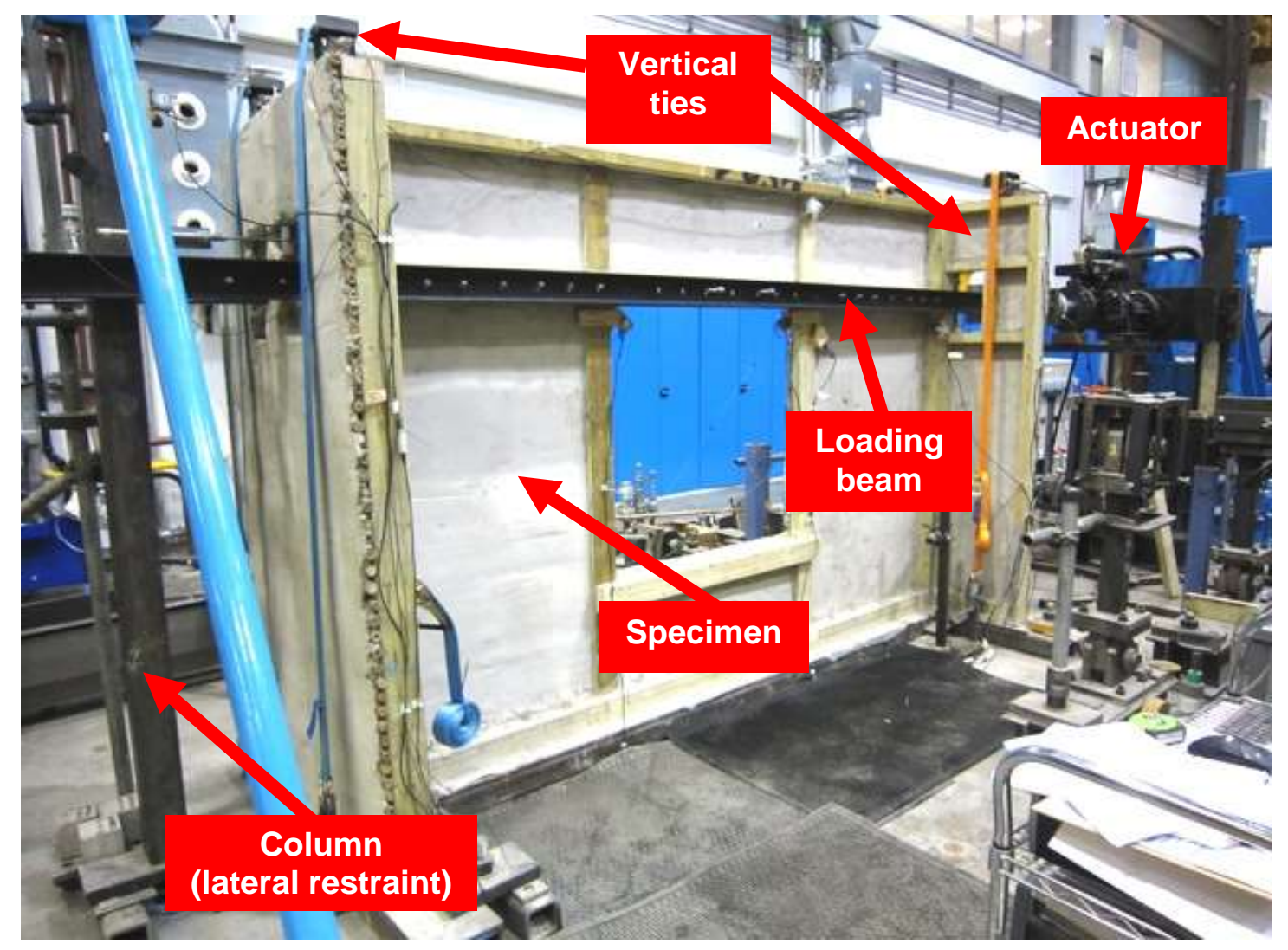

Figure 1. Experimental set-up 


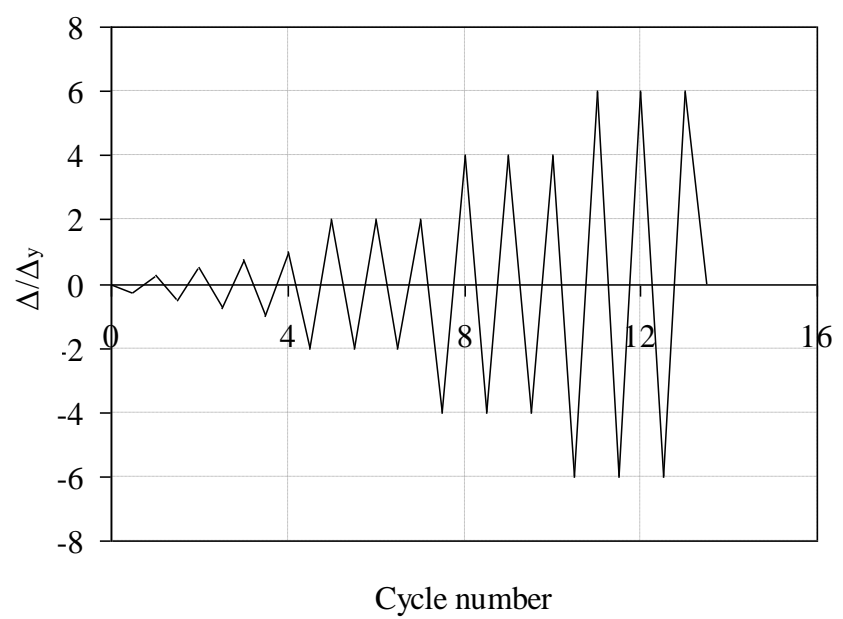

Figure 2. Loading protocol 
a) Type A
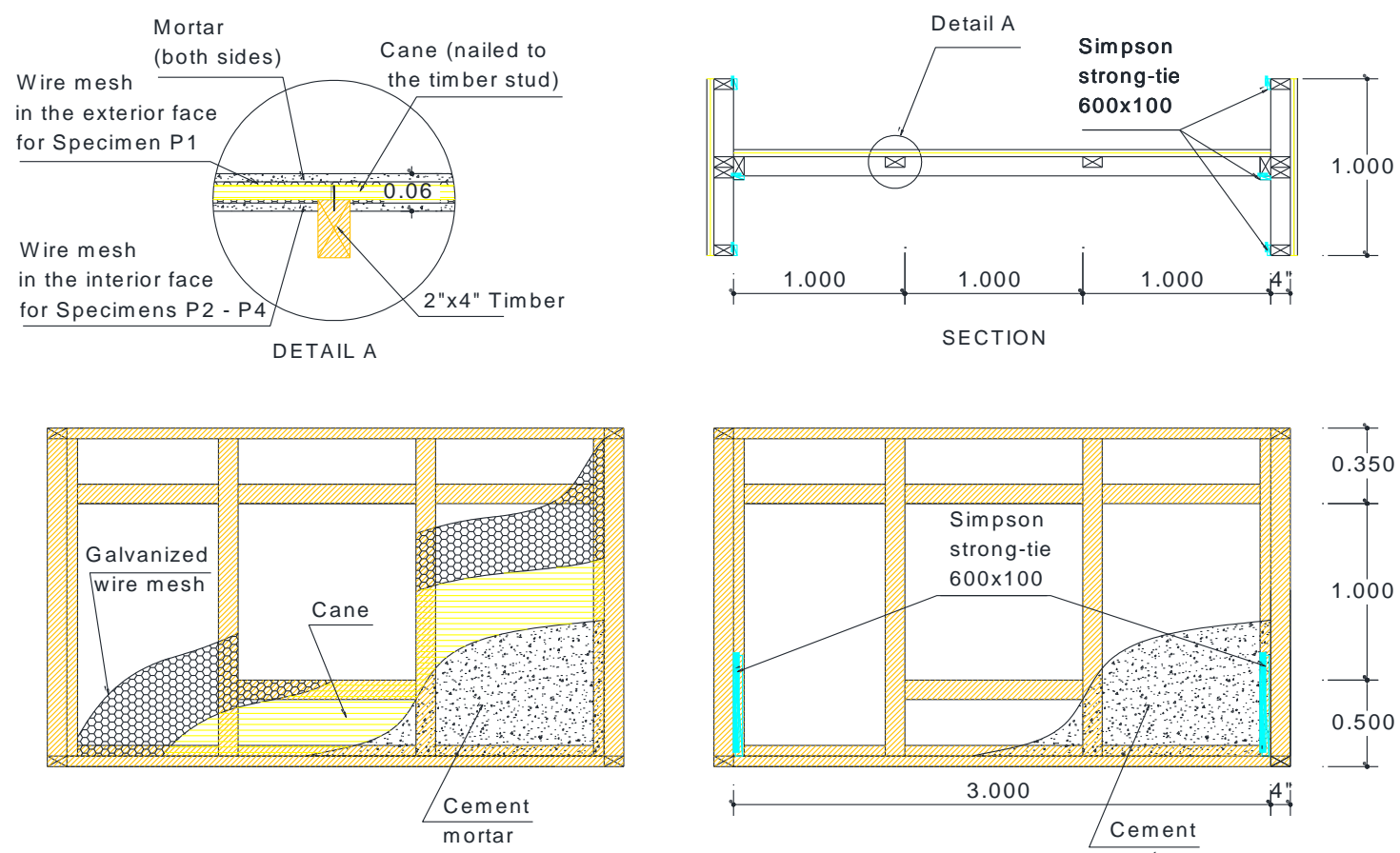

EXTERIOR SIDE

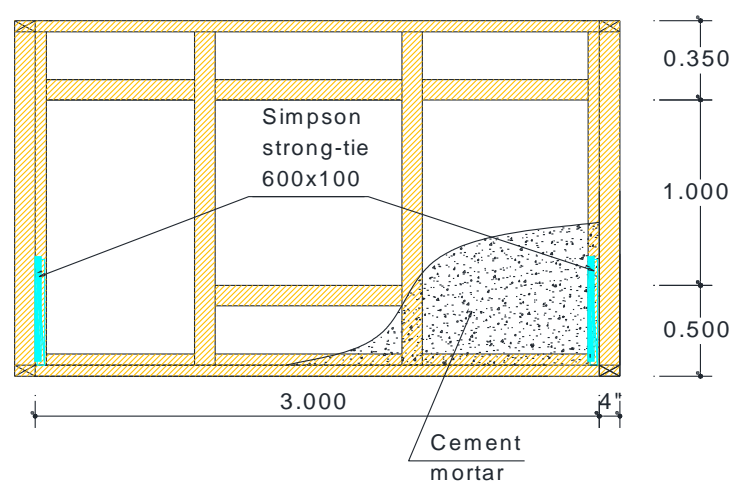

INTERIOR SIDE

b) Type B

Mortar
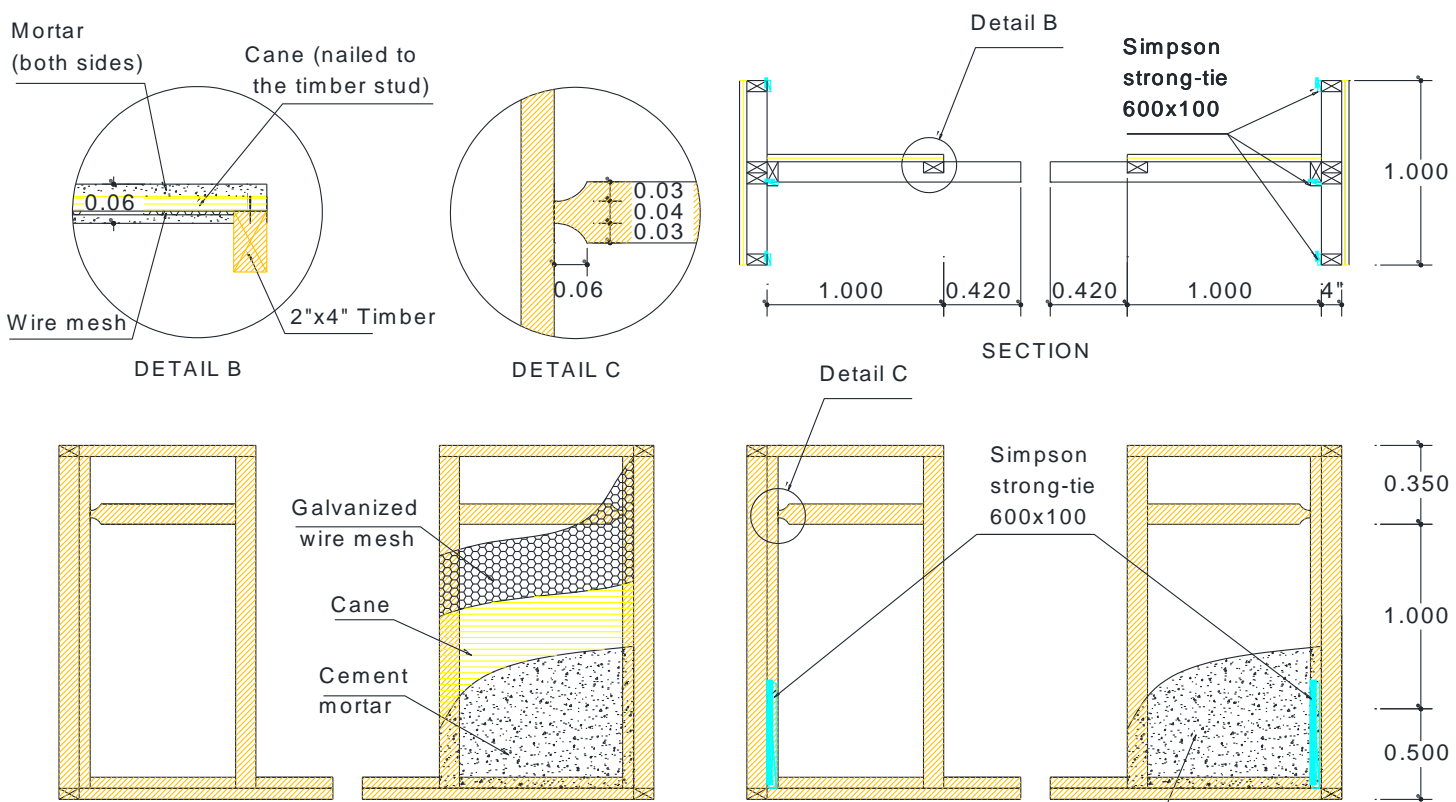

EXTERIOR SIDE

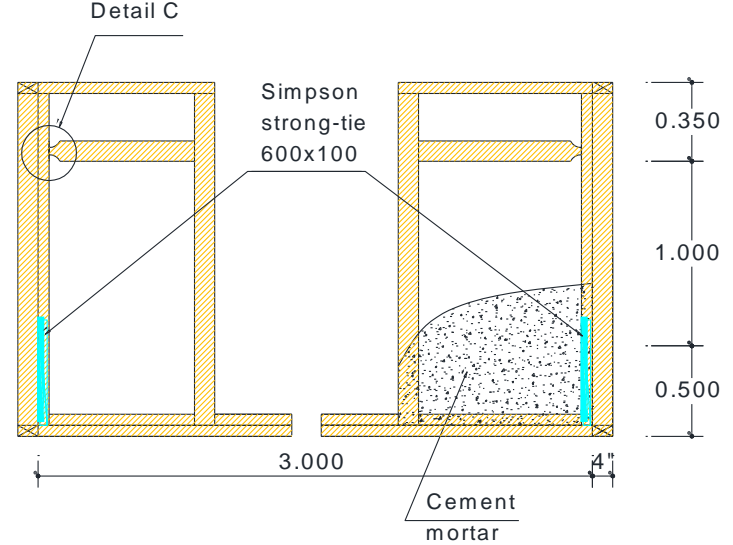

Figure 3. Details of panel configurations 


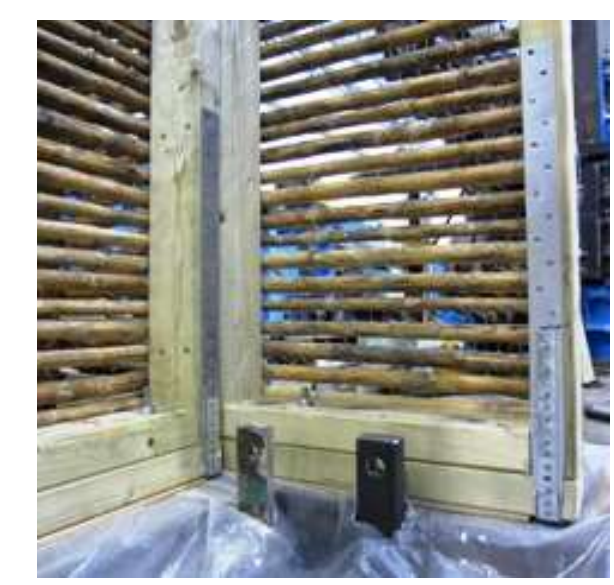

Figure 4. Detail of steel straps at the specimen ends 
a) Specimen P1

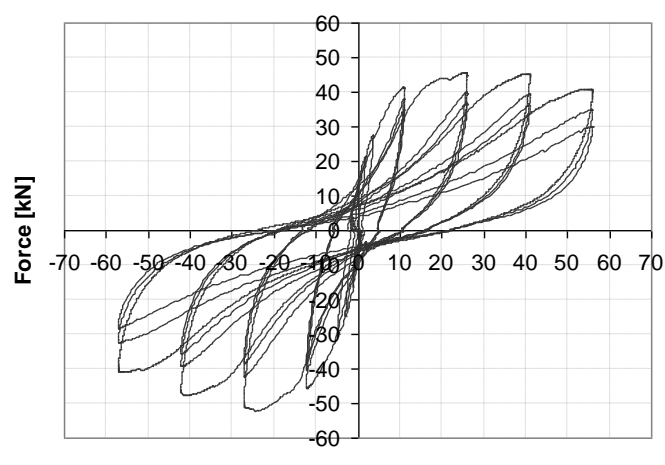

c) Specimen P3

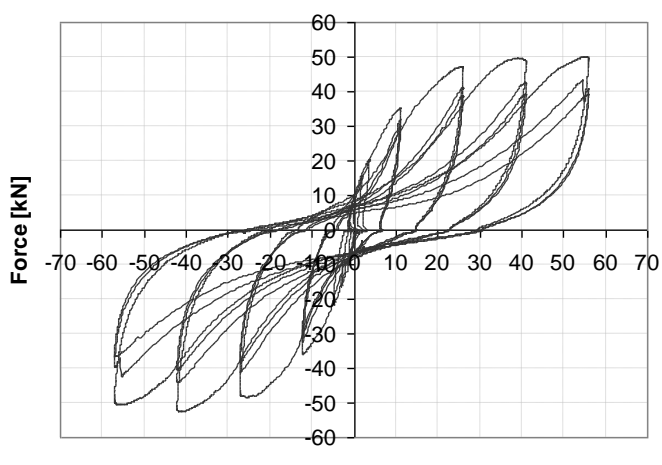

b) Specimen P2

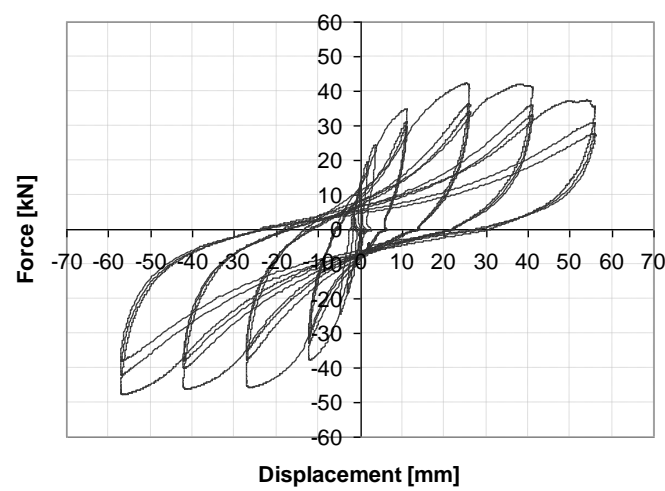

d) Specimen P4

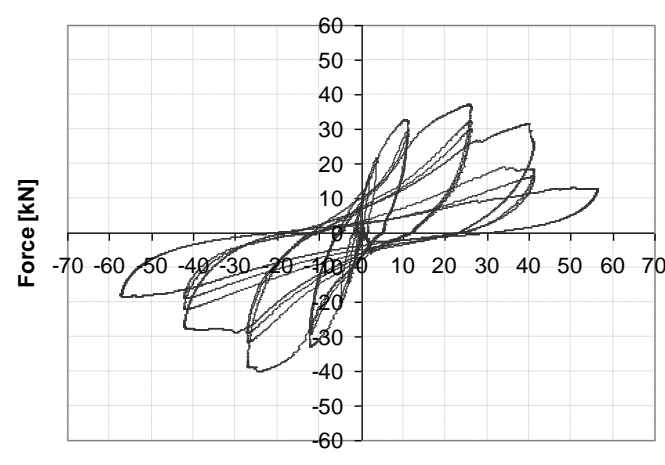

Displacement [mm]

e) Specimen P5

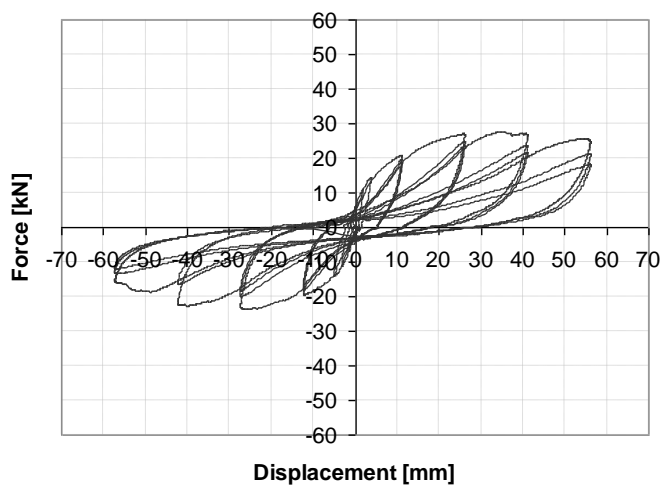

Figure 5. Force-displacement hysteresis 


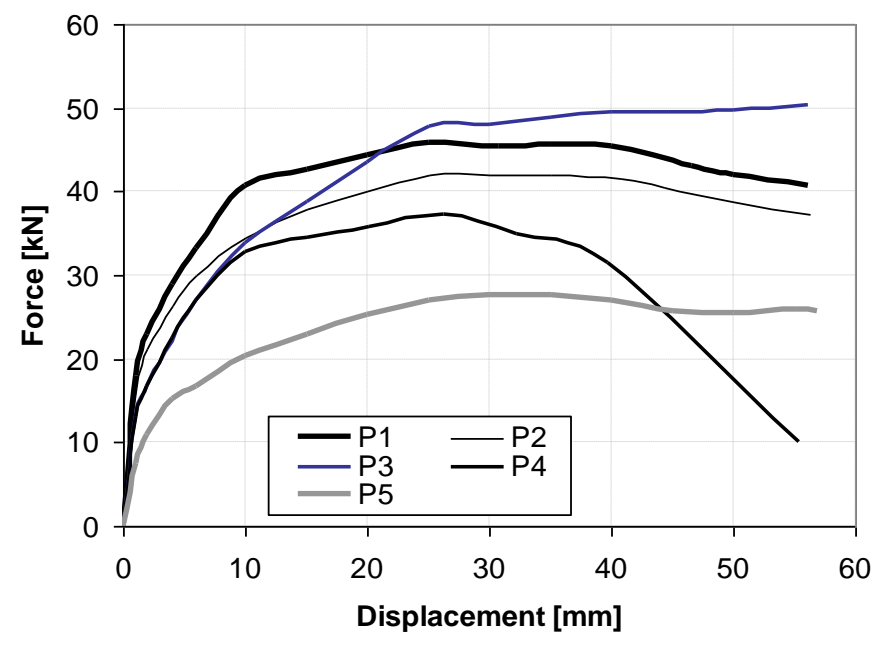

Figure 6. Envelopes of the force-displacement hysteresis

a) Specimen P1

b) Specimen P2
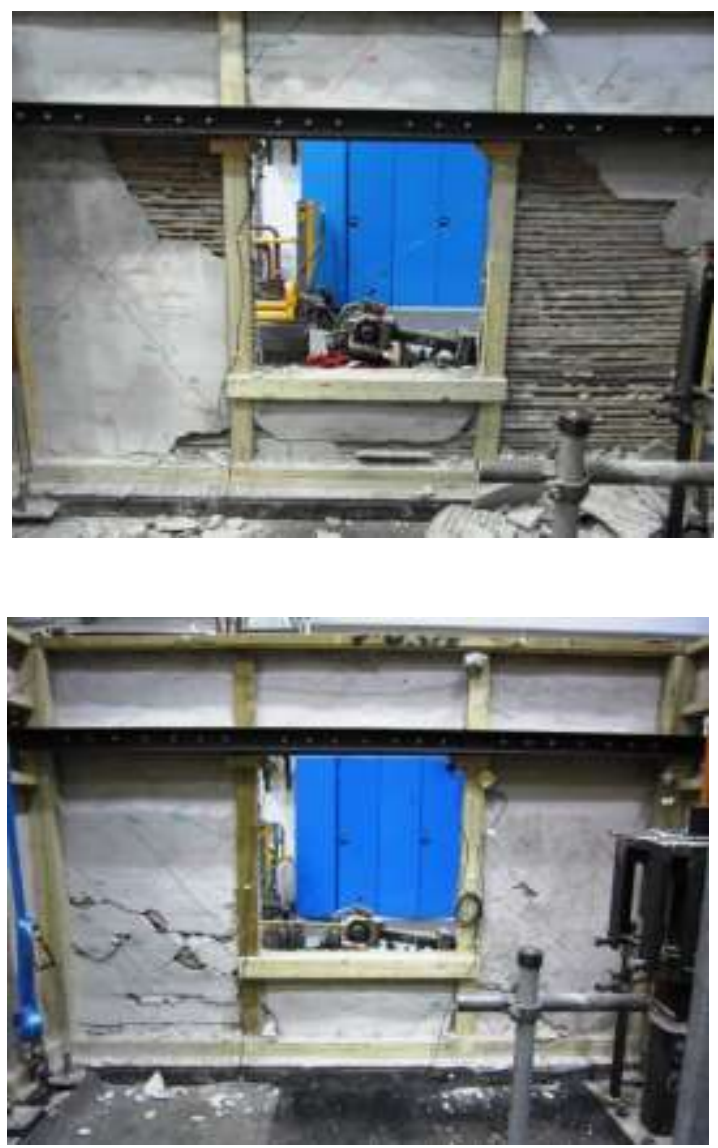

Figure 7. Damage state of the interior face at the end of test 


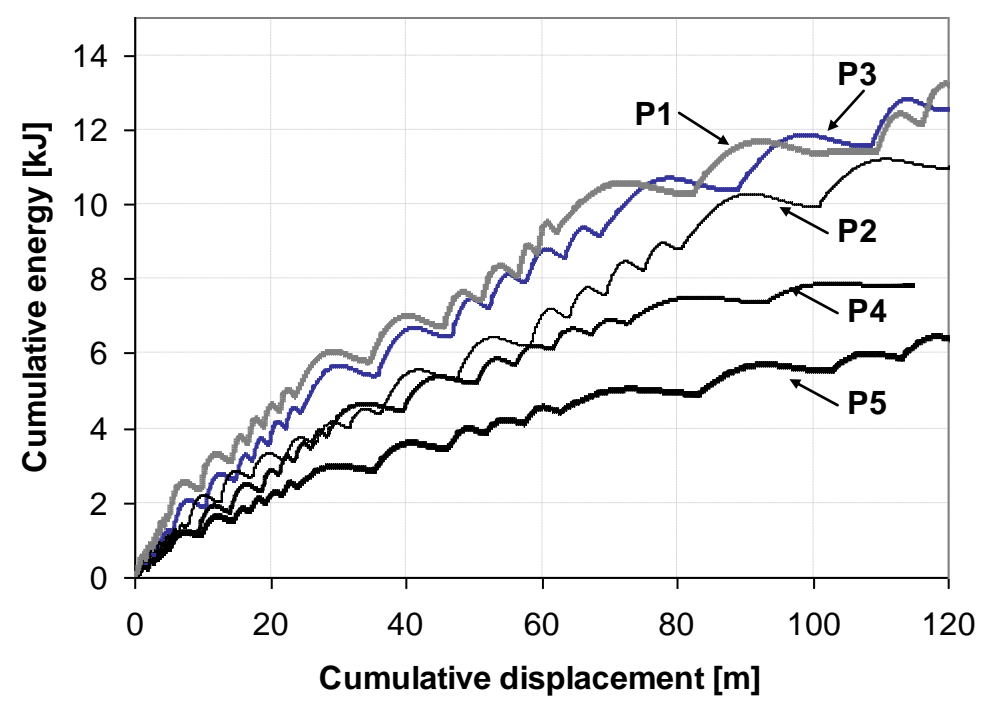

Figure 8. Cumulative energy dissipation 
a)

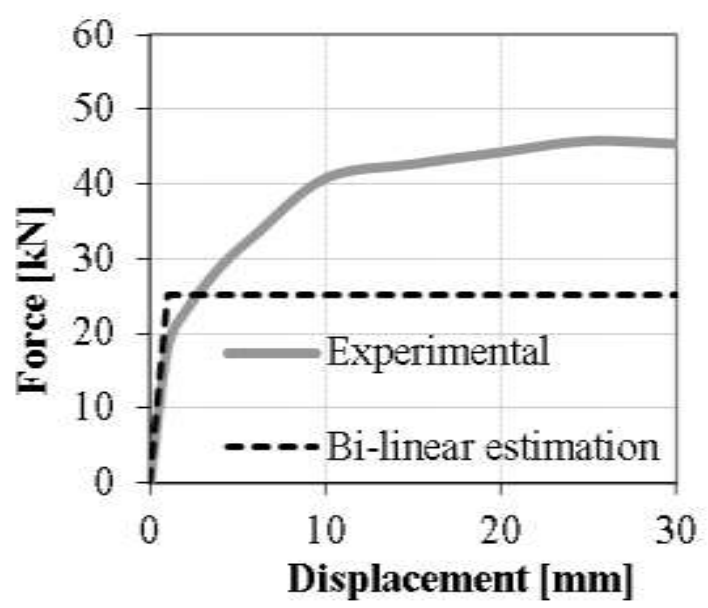

c)

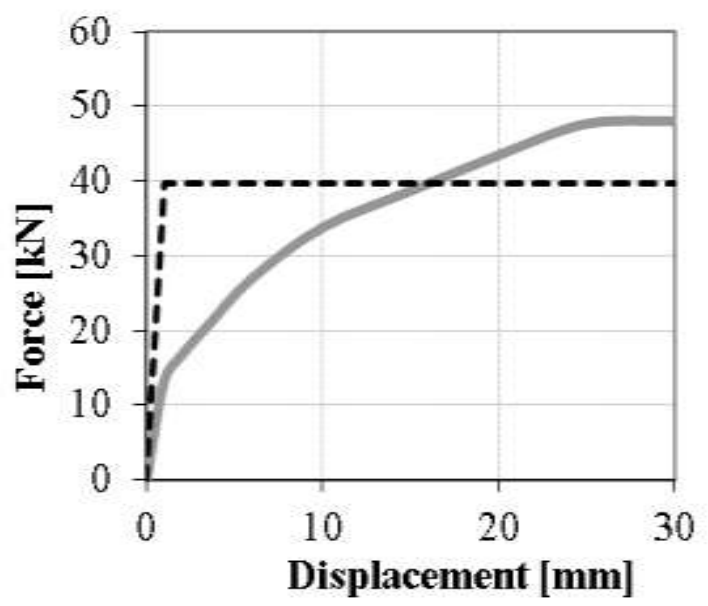

b)

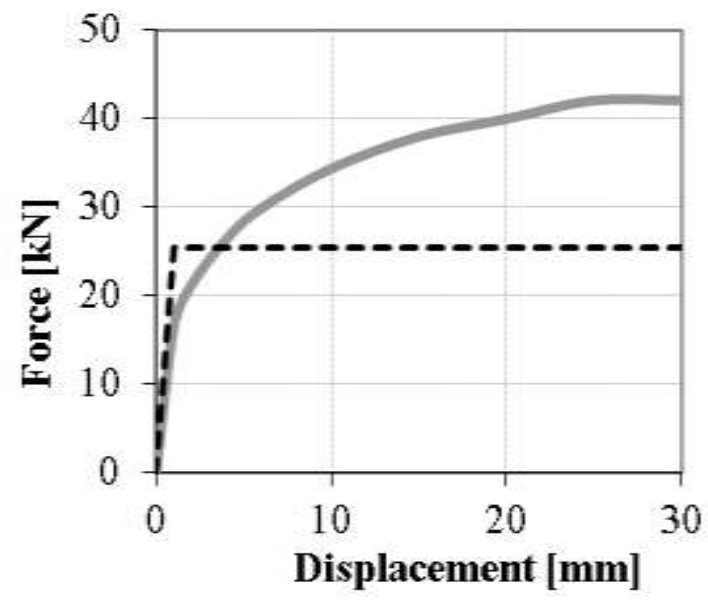

d)

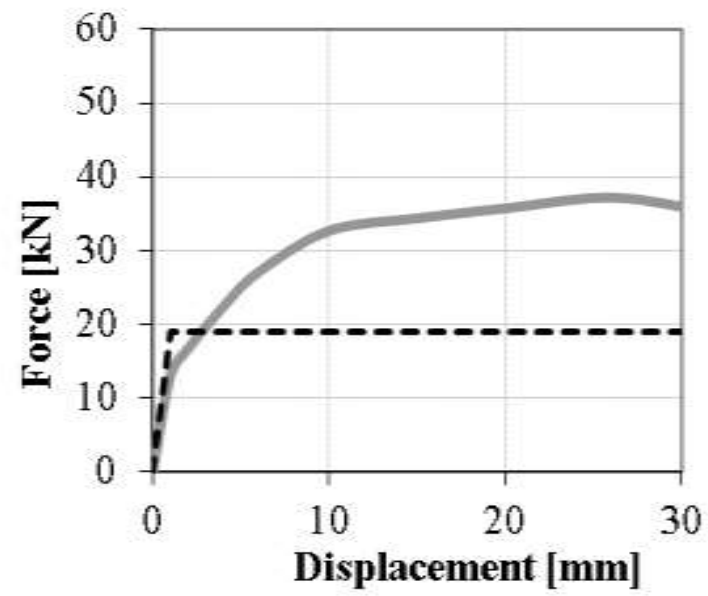

e)

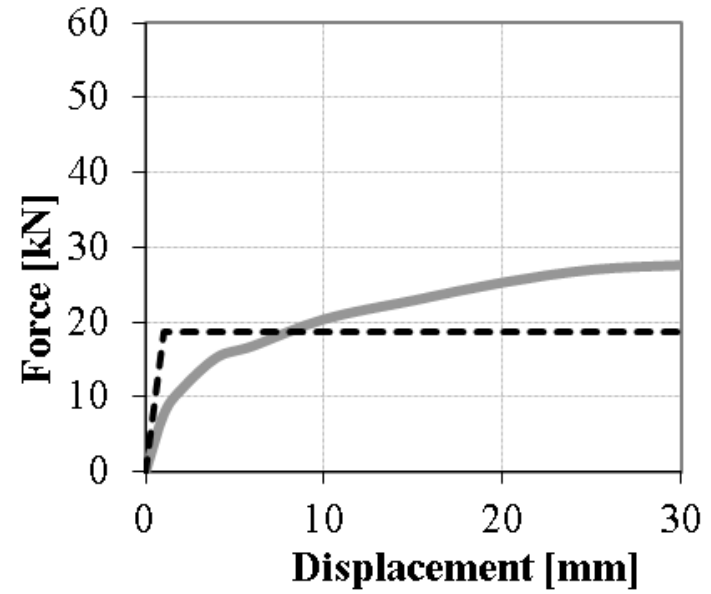

Figure 9. Comparison of envelope cyclic response and predicted force-displacement relationships 